\title{
The combined endocrine receptor in breast cancer, a novel approach to traditional hormone receptor interpretation and a better discriminator of outcome than ER and PR alone
}

\author{
Esther J Campbell ${ }^{\star}, 1,2$, Mathias Tesson ${ }^{2}$, Flora Doogan ${ }^{1}$, Zahra MA Mohammed ${ }^{2,3}$, Elizabeth Mallon ${ }^{4}$ and \\ Joanne Edwards ${ }^{2}$ \\ ${ }^{1}$ Department of Surgery, Queen Elizabeth University Hospital, Glasgow G51 4TF, UK; ${ }^{2}$ Institute of Cancer Sciences, University of \\ Glasgow, Wolfson Wohl Translational Cancer Research Centre, Garscube Estate, Glasgow G61 1HQ, UK; ${ }^{3}$ Academic Unit \\ of Colorectal Surgery, School of Medicine, University of Glasgow, Glasgow Royal Infirmary, Glasgow G4 OET, UK and ${ }^{4}$ Department \\ of Pathology, Queen Elizabeth University Hospital, Glasgow G51 4TF, UK
}

Background: The functional role of progesterone receptor (PR) signalling was previously unclear and PR testing in breast cancer is controversial. Recent defining work has highlighted the functional crosstalk that exists between the oestrogen receptor (ER) and PR. The purpose of this retrospective cohort study was to compare the prognostic value of the combined ER and PR score with either ER or PR alone.

Methods: Tumour Allred ER and PR scores were reclassified as negative, low and high. The combined endocrine receptor (CER) was calculated as the average of the reclassified ER and PR scores, resulting in three groups: CER negative, impaired and high. Cox proportional hazards models were used to estimate disease-free survival (DFS) and breast cancer-specific survival (BCSS).

Results: The CER was a more powerful predictor of 5-year DFS and BCSS than either ER or PR alone. In multivariate analysis that included ER, PR and CER, only CER remained an independent prognostic variable for 5-year DFS (hazard ratio (HR) 0.393; Cl: 0.283-0.548, $P=0.00001)$ and BCSS (HR 0.553; Cl: 0.423-0.722; $\left.P=2.506 \times 10^{-8}\right)$. In ER-positive (ER+) patients impaired CER was an independent marker of poor outcome for 5-year DFS (HR 2.469; Cl: 1.049-5.810; $P=0.038$ ) and BCSS (HR 1.946; Cl: 1.054-3.596; $P=0.033$ ) in multivariate analysis that included grade, lymph node, tumour size, HER2 status and PR status. The results were validated in a separate cohort of patients.

Conclusions: Combined endocrine receptor is a more powerful discriminator of patient outcome than either ER or PR alone. Economical and simple, it can identify risk in ER + early breast cancer and potentially be used for adjuvant cytotoxic chemotherapy decision-making.

Worldwide breast cancer is the most frequently diagnosed cancer in woman. The majority, $\sim 70 \%$, express the oestrogen receptor (ER). Oestrogen receptor-positive $(\mathrm{ER}+)$ disease has historically been perceived as the 'lesser of two evils', yet many women with
$\mathrm{ER}+$ breast cancer still succumb to their disease. Breast cancer is responsible for over 10000 deaths each year in the United Kingdom (http: //www.cancerresearchuk.org) and remains the leading cause of cancer deaths among females in less developed

*Correspondence: Dr EJ Campbell; E-mail: esther.campbell@ggc.scot.nhs.uk

Received 20 April 2016; revised 26 May 2016; accepted 7 June 2016; published online 22 September 2016

(c) 2016 Cancer Research UK. All rights reserved 0007-0920/16 
countries (Torre et al, 2015). The advent of gene expressing profiling and multiparametric assays has brought to the fore that $\mathrm{ER}+$ breast cancer is a heterogeneous disease and highlights the importance of targeted individual treatment selection (Paik et al, 2006; Dowsett et al, 2010). For most of the world, these validated methods to stratify risk and guide treatment decisions are too expensive and subsequently not routinely available. As recognised by the St Gallen conference, surrogate markers or less expensive pathology tests may provide valuable information in such countries (Coates et al, 2015).

Semiquantitative immunohistochemistry (IHC) is a nearuniversal method of tumour hormone receptor (ER and progesterone receptor, PR) testing. Tumour ER expression is a powerful predictor of response to endocrine therapy and its value is undisputed. Until recently, the biological role of PR was less well defined and it was considered a biomarker of ER function (Horwitz and McGuire, 1975). Oestrogen receptor-positive/progesterone receptor-positive $(\mathrm{PR}+)$ tumours are associated with better clinical outcome (Viale et al, 2007; Blows et al, 2010; Purdie et al, 2014); however, the underlying mechanism responsible for this was poorly understood. Recent, defining work has now elucidated that PR redirects where ER binds to chromatin and acts as a proliferative brake in ER + breast cancer (Mohammed et al, 2015). This highlights the role of functional crosstalk between both the ER and PR (Mohammed et al, 2015) and underlines the value of both ER and PR testing in breast cancer.

In this study, we hypothesised that semiquantitative IHC ER and PR scores together may represent a surrogate 'snap shot' of functional hormone receptor crosstalk. We therefore analysed the ER and PR together as a combined endocrine receptor (CER) to test if this would be more informative of outcome than either factor independently. We report that the CER is a better predictor of outcome than either the ER or PR, and the CER is an independent significant prognostic factor. The results were validated in a separate cohort of breast cancer patients.

\section{PATIENTS AND METHODS}

Derivation study patient population. One thousand seven hundred and eleven female patients were diagnosed with primary operable invasive breast cancer (symptomatic and screen detected) between October 1995 and September 1998 in Greater Glasgow NHS hospitals. The Greater Glasgow Breast Cancer (GGBC) database contains pathological, treatment and follow-up details for these patients. Original pathology report included \% tumour cells staining for ER. Progesterone receptor was not routinely tested during this period. Tumour samples were centrally reanalysed for 557 patients, randomly selected from the 1711 patients (33\%) (Supplementary Figure 1A). All patients in this cohort received tamoxifen monotherapy for 5 years except for two whose prescribed endocrine agent was not documented as they were enrolled in the ATAC study. The Research Ethics Committee of North Glasgow University Hospital approved the collection of patient data and use of human tissue in this study.

Tissue microarray construction and IHC. We have previously described the method for the tissue microarray (TMA) construction using formalin-fixed paraffin-embedded tissue, taken at the time of surgical resection (Mohammed et al, 2012a, b). Triplicate TMA were constructed to avoid heterogeneity of PR staining (Mohammed et al, 2012a). The IHC for ER, PR and HER2 was performed as we described previously (Mohammed et al, 2012a, b) applying protocols established in the CPA-accredited diagnostic pathology laboratory, Glasgow Royal Infirmary with appropriate positive and negative controls.

IHC scoring. Tumour Allred ER and PR scores were scored as we have previously reported (Mohammed et al, 2012a). A cutoff to define receptor positivity for $\mathrm{ER}$ and $\mathrm{PR}$ was an Allred score $\geqslant 3$, the internationally accepted cutoff. High scores were defined as Allred 6-
8, and low scores as Allred 3-5. Representative examples of ER and PR staining for each scoring category are shown in Supplementary Figure 2. Human epidermal growth factor receptor 2 membrane staining was scored as described previously (Mohammed et al, 2012b).

Combined endocrine receptor. The Allred ER and PR scores were reclassified. A score of 0 was assigned to an Allred score of $<3,1$ assigned to Allred scores $3-5$ and 2 assigned to Allred scores 6-8. The CER was calculated as the average of the reclassified ER and PR scores. Combined endocrine receptor 0 represents negative endocrine receptor status, CER 0.5-1.5 represents impaired endocrine receptor status (CER impaired) and CER 2 represents high endocrine receptor status (CER high).

Validation study patient population. The validation cohort of patients consisted of a consecutive series of new diagnosed early invasive female breast cancer patients presenting at two Greater Glasgow Hospitals between January 2008 and January 2009 (Supplementary Figure 1B). The Caldicott Guardian granted permission for the use of patient data. All patients underwent curative surgery and adjuvant treatment prescriptions as per national guidelines (SIGN, 2007) were discussed at a postoperative multidisciplinary meeting. Oestrogen receptor and PR IHC Allred scores for this cohort were obtained from routine pathology records.

Follow-up. Follow-up data was confirmed with the registrar general and patient case records for the derivation study patient population included survival status (alive, death other cause and breast cancer-specific death) and documentation of date and site of recurrence (none, local, regional, distant). For patients who died, the date of death was recorded; all deaths not attributable to breast cancer were censored at the date of death. The primary outcomes in this analysis were time from definitive surgery to breast cancerspecific death and time to recurrence. In addition, early 5-year disease-free survival (DFS) was analysed by censoring events at 5 years. Disease-free survival was defined as alive and well with no documented local, regional or distant breast cancer recurrence or breast cancer-specific death. Accordingly, the end points were breast cancer-specific survival (BCSS) and DFS at 5 years.

The validation study patient population follow-up was confirmed using electronic case records. For every patient, details of definitive surgery date and most recent clinical review date were collected to calculate time to outcome. Clinical review included either breast surgery follow-up clinic or oncology follow-up clinic. For patients who died, the date of death was recorded; all deaths not attributable to breast cancer were censored at the date of death. Patient status at most recent review date was recorded (alive and well, documented local, regional or distant breast cancer recurrence or breast cancer-specific death). The end point was DFS.

Statistical analysis. Statistical analysis was carried out using SPSS version 22 (IBM, New York, NY, USA). Univariate survival analysis was performed using Kaplan-Meier method analysed by the log-rank test. Calculation of hazard ratios (HRs) for both univariate and multivariate analysis was performed using Cox's proportional-hazards model; a stepwise backward procedure was used to derive a final model of variables that had a significant independent relationship with patient outcome.

\section{RESULTS}

Derivation study population. A total of 1711 patients presented with operable invasive breast cancer from October 1995 to September 1998. Five hundred and fifty-seven patient tumour samples were randomly selected for TMA construction and centrally tested for ER and PR. Male breast cancers were excluded because of their biological heterogeneity. Accurate follow-up data and tumour Allred scores for ER and PR were available for $90 \%$ 
$(n=503)$ patients. Sixty-three per cent $(n=319)$ were ER + and $42 \%(n=210)$ were $\mathrm{ER}+/ \mathrm{PR}+$. Patient and tumour characteristics are detailed in Table 1. Median follow-up was 12.7 years, $61 \%$ $(n=305)$ patients were alive, $20 \%(n=102)$ had died as a result of breast cancer and $19 \%(n=96)$ had died from other causes. At 5 years, $16 \%(n=82)$ had a breast cancer-specific event.

CER scores (0-2). Combined endocrine receptor score $(0,0.5,1$, $1.5,2)$ survival analysis confirmed the selected cutoffs (Figure 1) defining the classification of negative (CER 0), impaired (CER 0.5-1.5) and high (CER2). Combined endocrine receptor 0 (HR 6.915; CI: 3.131-15.264; $P=0.000002$ ), CER 0.5 (HR 3.418; CI: 1.085-10.771; $P=0.036)$, CER 1 (HR 2.617; CI: $1.044-6.560 ; P=0.040)$ and CER 1.5 (HR 3.031; CI: 1.099-8.360; $P=0.032$ ) with CER 2 as the indicator category.

Table 1. Characteristics of the derivation study population

\begin{tabular}{|c|c|c|c|c|}
\hline & $\begin{array}{l}\text { Total } \\
N(\%)\end{array}$ & $\begin{array}{c}\text { CER }_{\text {neg }} \\
N(\%)\end{array}$ & $\begin{array}{c}\text { CER }_{\text {imp }} \\
N(\%)\end{array}$ & $\begin{array}{l}\text { CER }_{\mathrm{hi}} \\
N(\%)\end{array}$ \\
\hline \multicolumn{5}{|l|}{ Age (years) } \\
\hline$<50$ & $144(29)$ & $63(37)$ & $43(23)$ & $38(27)$ \\
\hline$\geqslant 50$ & $359(71)$ & $109(63)$ & $146(77)$ & $104(73)$ \\
\hline \multicolumn{5}{|l|}{ Grade } \\
\hline 1 & $93(18)$ & $3(2)$ & $51(27)$ & $39(27)$ \\
\hline 2 & $217(43)$ & 33 (19) & $108(57)$ & $76(53)$ \\
\hline 3 & $191(38)$ & $134(78)$ & $30(16)$ & $27(19)$ \\
\hline Unknown & $2(<1)$ & $2(1)$ & & \\
\hline \multicolumn{5}{|l|}{ Lymph node } \\
\hline 0 & $287(57)$ & $95(55)$ & $109(58)$ & $83(58)$ \\
\hline $1-3$ & $129(26)$ & $39(23)$ & $52(28)$ & $38(27)$ \\
\hline$>3$ & $81(16)$ & $37(21)$ & $26(14)$ & $18(13)$ \\
\hline Unknown & $6(1)$ & $1(<1)$ & $2(<1)$ & $3(2)$ \\
\hline \multicolumn{5}{|l|}{ Size $(\mathrm{mm})$} \\
\hline$<20$ & 297 (59) & $83(49)$ & $121(64)$ & $93(66)$ \\
\hline $20-50$ & $189(38)$ & $81(47)$ & $62(33)$ & $46(32)$ \\
\hline$>50$ & $16(3)$ & $7(4)$ & $6(3)$ & $3(2)$ \\
\hline Unknown & $1(<1)$ & $1(<1)$ & & \\
\hline \multicolumn{5}{|c|}{ ER Allred score } \\
\hline$<3$ & $184(37)$ & $172(100)$ & $12(6)$ & \\
\hline $3-5$ & $56(11)$ & & $56(30)$ & \\
\hline $6-8$ & $263(52)$ & & $121(64)$ & $142(100)$ \\
\hline \multicolumn{5}{|c|}{ PR Allred score } \\
\hline$<3$ & $281(56)$ & $172(100)$ & $109(58)$ & \\
\hline $3-5$ & $57(11)$ & & $57(30)$ & \\
\hline $6-8$ & 165 (33) & & $23(12)$ & $142(100)$ \\
\hline \multicolumn{5}{|l|}{ HER2 } \\
\hline Positive & $76(15)$ & $51(30)$ & $16(9)$ & $9(6)$ \\
\hline Negative & $417(83)$ & $117(68)$ & $169(89)$ & $131(92)$ \\
\hline Unknown & $10(2)$ & $4(2)$ & $4(2)$ & $2(2)$ \\
\hline \multicolumn{5}{|c|}{ Surgical operation } \\
\hline Mastectomy & $322(64)$ & $105(61)$ & $125(66)$ & $92(65)$ \\
\hline Conservation & $181(36)$ & $67(39)$ & $64(34)$ & $50(35)$ \\
\hline \multicolumn{5}{|c|}{ Endocrine therapy } \\
\hline Yes & $368(73)$ & $69(40)$ & $170(90)$ & $129(91)$ \\
\hline No & $127(25)$ & $100(58)$ & $16(8)$ & $11(8)$ \\
\hline Unknown & $8(2)$ & $3(2)$ & $3(2)$ & $2(1)$ \\
\hline \multicolumn{5}{|c|}{ Chemotherapy } \\
\hline Yes & $208(42)$ & $116(67)$ & $49(26)$ & $43(30)$ \\
\hline No & $292(58)$ & 55 (32) & $138(73)$ & $99(70)$ \\
\hline Unknown & $3(<1)$ & $1(<1)$ & $2(1)$ & \\
\hline
\end{tabular}

Abbreviations: $C E R=$ combined endocrine receptor; $\mathrm{ER}=$ oestrogen receptor; HER2 =

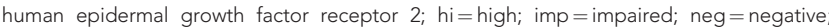
$\mathrm{PR}=$ progesterone receptor. For the derivation population study, patient and tumour characteristics in the column titled 'total' are recategorised according to the CER classification.
Redistribution of endocrine response using the CER compared with ER. Of the $319 \mathrm{ER}+$ patients, 263 patients had an Allred ER high (6-8), when the CER was applied, and $46 \%(n=121)$ of these patients were reclassified as impaired. In addition, $6 \%(n=12)$ of ER - were reclassified as CER impaired (Table 1).

CER and patient outcome. The CER classification resulted in a statistically significant difference in both early 5 -year DFS and BCSS between negative, impaired and high categories (Figure 2A and D). No statistical difference was demonstrated between ER high and low (Figure $2 \mathrm{~B}$ and $\mathrm{E}$ ) or $\mathrm{PR}-$ and low (Figure $2 \mathrm{C}$ and $\mathrm{F}$ ).

Multivariate analysis. Survival analysis confirmed that tumour grade, tumour size and lymph node (LN) (0 nodes positive, 1-3 nodes positive and $>3$ nodes positive) and HER2 positivity were all predictive of prognosis (data not shown).

The CER was a more powerful predictor of 5 -year DFS and BCSS than either the ER or PR alone. In multivariate analysis that included ER, PR and CER, only the CER remained an independent prognostic variable for 5-year DFS (HR 0.393; CI: 0.283-0.548; $P=0.00001$ ) and BCSS (HR 0.553; CI: 0.423-0.722; $P=2.506$ $\times 10^{-8}$ ). In multivariate analysis that included grade, $\mathrm{LN}$, tumour size category and HER2 status, CER impaired and negative were independent prognostic variables with CER high as the indicator category for 5-year DFS (Table 2). In terms of BCSS for the entire cohort, impaired CER was not statistically significant when analysed as a categorical variable (Table 2).

In contrast in subgroup analysis performed in ER + patients $(n=319)$, therefore excluding CER-negative patients, impaired CER was an independent marker of poor outcome for 5 -years DFS and BCSS (Table 2) in multivariate analysis that included grade, LN, tumour size, HER2 status and PR status. Importantly, for 5 -year DFS, impaired CER was a better predictor of outcome than PR status, tumour size and tumour grade (Table 2).

Validation study population. Validation of the prognostic power of the CER was performed in 455 patients diagnosed with early invasive operable breast cancer between January 2008 and January 2009. Patient and tumour characteristics are detailed in Table 3.

There were notable differences between the study cohorts. The validation cohort had fewer patients with ER - breast cancer and

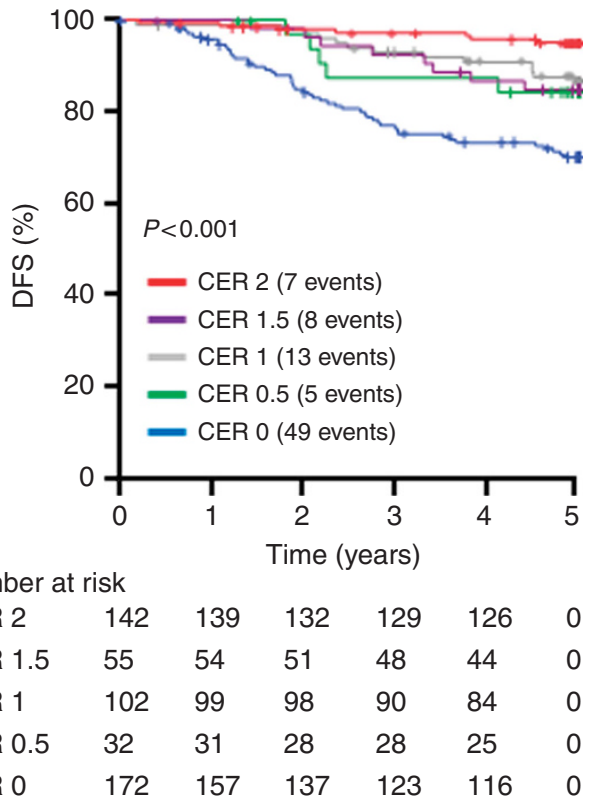

Figure 1. Determination of the cutoffs for the CER. Kaplan-Meier plots were constructed for all possible CER values $0,0.5,1,1.5$ and 2 . The outcome is 5 -year DFS. 
A

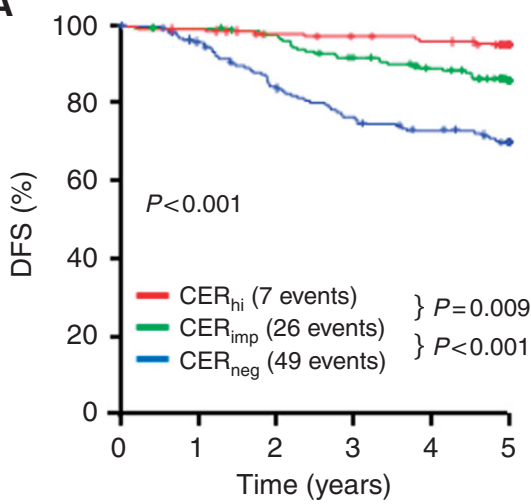

Number at risk

$\begin{array}{lllllll}\text { CER }_{\text {hi }} & 142 & 139 & 132 & 129 & 126 & 0 \\ \text { CER }_{\text {imp }} & 189 & 185 & 179 & 165 & 155 & 0 \\ \text { CER }_{\text {neg }} & 172 & 157 & 137 & 123 & 116 & 0\end{array}$

D

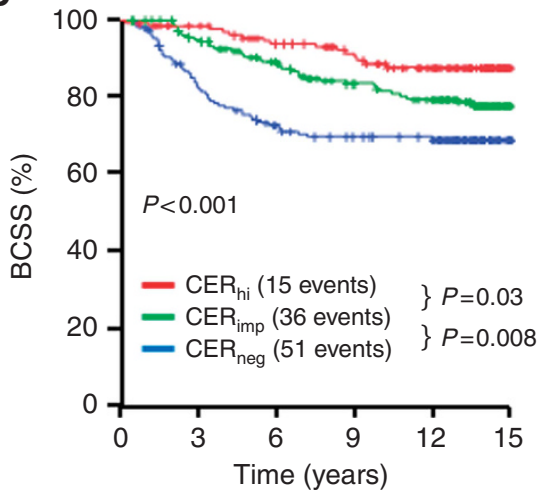

Number at risk

$\begin{array}{lllllll}\text { CER }_{\text {hi }} & 142 & 132 & 119 & 105 & 86 & 0 \\ \text { CER }_{\text {imp }} & 189 & 171 & 147 & 126 & 115 & 0 \\ \text { CER }_{\text {neg }} & 172 & 134 & 113 & 102 & 94 & 0\end{array}$

B

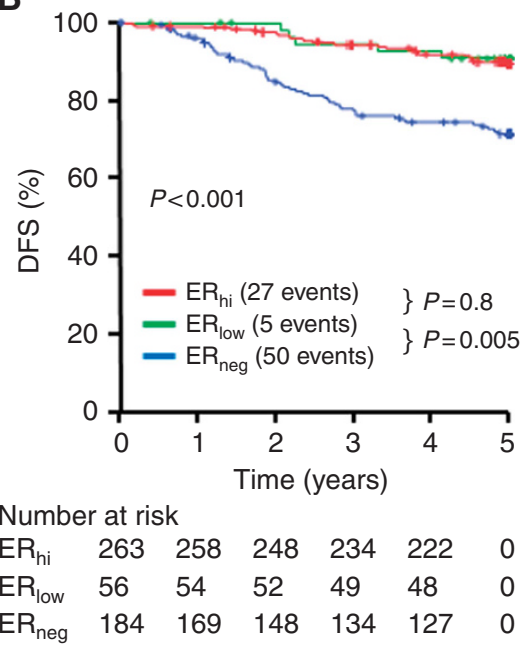

E

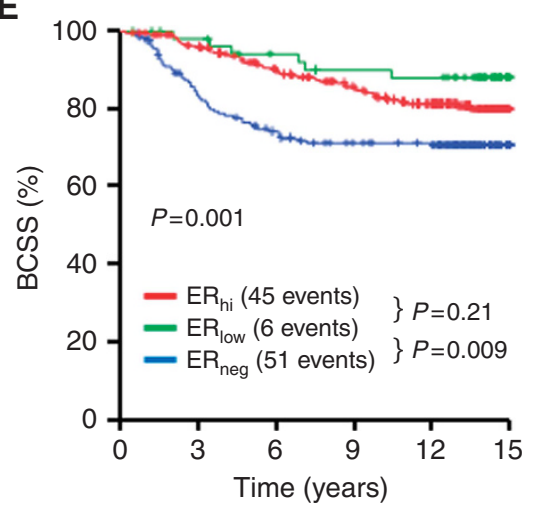

Number at risk

$\begin{array}{lllllll}\mathrm{ER}_{\text {hi }} & 263 & 241 & 208 & 180 & 151 & 0 \\ \mathrm{ER}_{\text {low }} & 56 & 51 & 46 & 42 & 41 & 0\end{array}$

$\begin{array}{lllllll}\mathrm{ER}_{\text {neg }} & 184 & 145 & 124 & 112 & 106 & 0\end{array}$
C

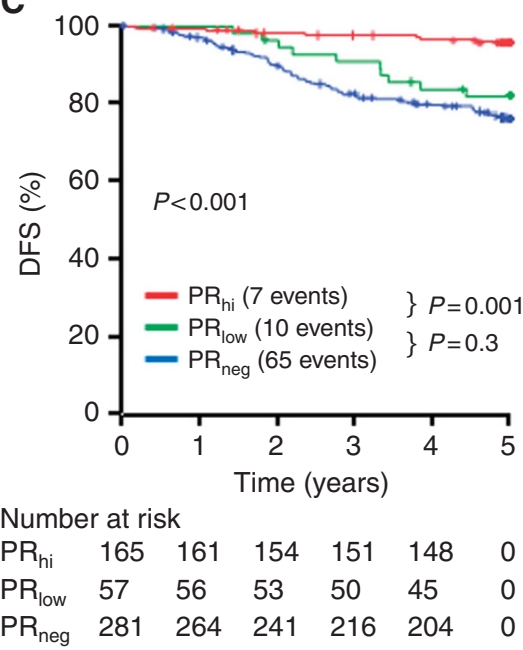

$\mathbf{F}$

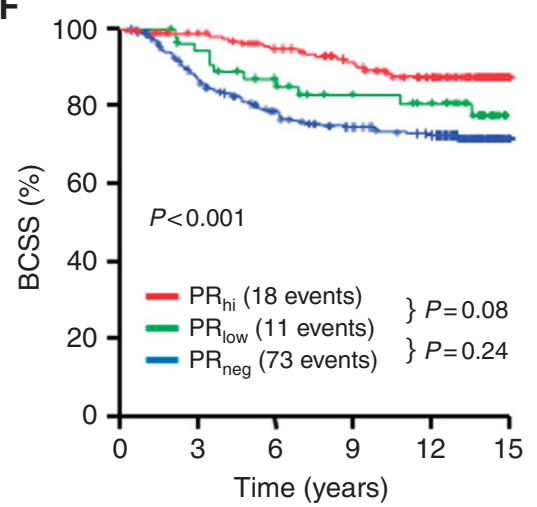

Number at risk

$\begin{array}{lllllll}\mathrm{PR}_{\mathrm{hi}} & 165 & 154 & 141 & 125 & 105 & 0\end{array}$

$\begin{array}{lllllll}\mathrm{PR}_{\text {low }} & 57 & 52 & 43 & 36 & 32 & 0\end{array}$

$\begin{array}{lllllll}\mathrm{PR}_{\text {neg }} & 281 & 232 & 195 & 173 & 161 & 0\end{array}$

Figure 2. Kaplan-Meier plots in the derivation study. Five-year DFS was plotted according to the CER scores (A), ER scores (B) or PR scores (C). Breast cancer-specific survival at 15 years was plotted according to CER scores (D), ER scores (E) or PR scores $(\mathbf{F})$. Hi $=$ high; imp $=i m p a i r e d ;$ neg $=$ negative.

PR - breast cancer. As expected with a more recent cohort, the majority of HER $2+$ patients received biological therapy and more patients underwent breast conservation surgery. More patients had $\mathrm{LN}$ - disease and were over 50 years at age, presumably as a result of improved breast screening uptake. Almost all (98\%) patients with $\mathrm{ER}+$ breast cancer received endocrine treatment.

Median follow-up was 68.25 months (5.7 years). Eighty per cent $(n=364)$ patients were alive and well, $7 \%(n=31)$ had died as a result of breast cancer and 9\% $(n=42)$ had died from other causes. Four per cent $(n=19)$ were alive with documented evidence of breast cancer recurrence; therefore, $11 \%(n=50)$ had a breast cancer-specific event.

Combined endocrine receptor classification in this cohort was associated with highly significant differences in DFS between CERnegative, CER impaired and CER high groups (Figure 3A). There was no significant difference in outcome between ER low and ER - (Figure 3B) or PR low and PR - (Figure 3C). The CER was a more powerful predictor of DFS than either the ER or PR. In multivariate analysis comparing the three factors, the CER classification was independently significant, CER-negative HR 6.416 (CI: 3.129-13.157; $P=3.903 \times 10^{-7}$ ) and CER impaired HR 2.627 (CI: $1.327-5.202 ; P=0.006$ ). In multivariate analysis that included grade, tumour size and LN (HER2 was not included as this was not significantly associated with poor outcome as most
HER2 + patients received biological therapy), the CER was independently significant in the validation cohort, including ER + subgroup $(n=398)$ (Table 2$)$. The CER was a more powerful predictor of DFS than grade and tumour size (Table 2). Tumour size, grade and LN were independently significant for DFS as expected when included in multivariate analysis without CER (data not shown).

\section{DISCUSSION}

The CER is economical and an easily reproducible algorithm using well-validated routinely tested biomarkers. In the derivation study for patients with early breast cancer, the CER was observed to be a better predictor of DFS and BCSS than either ER or PR alone. In addition, the CER is independently significant in multivariate analysis when combined with grade, LN status and tumour size. These findings were validated in a separate, modern cohort of early breast cancer patients.

Semiquantitative IHC is the near universal choice of tumour hormone (ER and PR) receptor testing. Despite its widespread use there have been a number of controversies in recent years regarding hormone testing. 
Immunohistochemistry is a semiquantitative technique and preanalytical, analytical and postanalytical factors can influence the results and result in test variation (Allred et al, 2009). In the derivation study, expression levels of both receptors were centrally tested to avoid testing variation. The validation study used the Allred scores from the pathology reports. The receptor testing had been performed in CPA accredited laboratories and represent 'realworld' data.

Immunohistochemistry assays of $\mathrm{ER}$ and $\mathrm{PR}$ are limited to determining whether the receptors are present in tumour cells and providing some information on the levels of ER and PR in the tumour. The primary purpose of evaluating the ER and/or PR status for individual patients is to predict whether they will respond to endocrine therapy. For the purposes of selecting endocrine therapy, it is the hormone receptor status that is primarily important. It is notable, however, that $6 \%$ of patients of ER - patients were reclassified as CER impaired $(E R-/ P R+)$ in the derivation cohort and $1 \%$ in the validation cohort, suggesting that the CER categorisation will ensure more patients with

Table 2. Multivariate Cox analysis for 5-year DFS and BCSS in the derivation and validation cohorts

\begin{tabular}{|c|c|c|}
\hline & Hazard ratio $(\mathrm{Cl})$ & Significance \\
\hline \multicolumn{3}{|l|}{ Derivation cohort } \\
\hline \multicolumn{3}{|l|}{ 5-year DFS } \\
\hline Lymph node & $1.895(1.453-2.472)$ & $P=0.00005$ \\
\hline Grade & $1.560(1.001-2.431)$ & $P=0.050$ \\
\hline Size & $1.380(0.918-2.173)$ & $P=0.121$ \\
\hline $\mathrm{CER}_{\text {neg }}$ & $4.441(1.895-10.411)$ & $P=0.001$ \\
\hline CER imp & $2.869(1.240-6.639)$ & $P=0.014$ \\
\hline HER2 + & $1.676(1.004-2.798)$ & $P=0.048$ \\
\hline \multicolumn{3}{|l|}{ BCSS } \\
\hline Lymph node & $1.833(1.428-2.353)$ & $P=0.000002$ \\
\hline Grade & $1.504(1.026-2.203)$ & $P=0.036$ \\
\hline Size & $1.711(1.196-2.448)$ & $P=0.003$ \\
\hline $\mathrm{CER}_{\text {neg }}$ & $2.024(1.065-3.848)$ & $P=0.031$ \\
\hline CER imp & $1.788(0.974-3.283)$ & $P=0.061$ \\
\hline HER2 + & $1.182(0.717-1.948)$ & $P=0.511$ \\
\hline \multicolumn{3}{|l|}{ 5-year DFS in ER + patients } \\
\hline Lymph node & $2.027(1.281-3.209)$ & $P=0.003$ \\
\hline Grade & $1.646(0.899-3.012)$ & $P=0.106$ \\
\hline Size & $1.208(0.639-2.35)$ & $P=0.561$ \\
\hline $\mathrm{CER}_{\text {imp }}$ & $2.469(1.049-5.810)$ & $P=0.038$ \\
\hline $\mathrm{PR}_{\text {neg }}$ & $0.956(0.409-2.236)$ & $P=0.917$ \\
\hline HER2 + & $4.160(1.803-9.603)$ & $P=0.001$ \\
\hline \multicolumn{3}{|l|}{ BCSS ER + patients } \\
\hline Lymph node & $2.070(1.406-3.049)$ & $P=0.0002$ \\
\hline Grade & $1.825(1.167-2.855)$ & $P=0.008$ \\
\hline Size & $1.723(1.167-2.806)$ & $P=0.029$ \\
\hline $\mathrm{CER}_{\text {imp }}$ & $1.946(1.054-3.596)$ & $P=0.033$ \\
\hline $\mathrm{PR}_{\text {neg }}$ & $0.928(0.464-1.858)$ & $P=0.833$ \\
\hline HER2 + & $1.535(0.644-3.629)$ & $P=0.329$ \\
\hline \multicolumn{3}{|l|}{ Validation cohort } \\
\hline \multicolumn{3}{|l|}{ DFS } \\
\hline Lymph node & $1.818(1.282-2.579)$ & $P=0.001$ \\
\hline Grade & $1.266(0.731-2.192)$ & $P=0.400$ \\
\hline Size & $1.416(0.825-2.428)$ & $P=0.207$ \\
\hline $\mathrm{CER}_{\text {neg }}$ & $5.722(2.727-12.003)$ & $P=0.000004$ \\
\hline CER imp & $2.431(1.196-4.941)$ & $P=0.014$ \\
\hline \multicolumn{3}{|l|}{ DFS in ER + patients } \\
\hline Lymph node & $2.388(1.554-3.671)$ & $P=0.00007$ \\
\hline Grade & $1.445(0.805-2.594)$ & $P=0.218$ \\
\hline Size & $1.299(0.680-2.480)$ & $P=0.428$ \\
\hline $\mathrm{CER}_{\text {imp }}$ & $2.096(1.010-4.351)$ & $P=0.047$ \\
\hline $\mathrm{PR}_{\text {neg }}$ & $0.763(0.299-1.948)$ & $P=0.571$ \\
\hline \multicolumn{3}{|c|}{$\begin{array}{l}\text { Abbreviations: } \mathrm{BCSS}=\text { breast cancer-specific survival; } \mathrm{CER}=\text { combined endocrine receptor } \\
\mathrm{Cl}=\text { confidence interval; } \mathrm{DFS}=\text { disease-free survival; } E R=\text { oestrogen receptor; } \mathrm{HER} 2+ \\
=\text { human epidermal growth factor receptor } 2 \text {-positive; imp=impaired; neg = negative } \\
\mathrm{PR}=\text { progesterone receptor. }\end{array}$} \\
\hline
\end{tabular}

hormone receptor-positive disease will be considered eligible for endocrine treatment.

The categorisation should be clinically useful in the context of guiding adjuvant chemotherapy. Importantly, in both cohorts a substantial number of patients with high Allred ER scores were reclassified as impaired using the CER. There is an open question regarding the importance of quantifying hormone receptor expression level by IHC. Fisher et al (2005) compared various methods of scoring $\mathrm{ER}$ and $\mathrm{PR}$, involving percentage ranges,

Table 3. Characteristics of the validation study population

\begin{tabular}{|c|c|c|c|c|}
\hline & $\begin{array}{l}\text { Total } \\
N(\%)\end{array}$ & $\begin{array}{c}\text { CER }_{\text {neg }} \\
N(\%)\end{array}$ & $\begin{array}{c}\text { CER }_{\text {imp }} \\
N(\%)\end{array}$ & $\begin{array}{l}\text { CER }_{\text {hi }} \\
N(\%)\end{array}$ \\
\hline \multicolumn{5}{|l|}{ Age (years) } \\
\hline$<50$ & $68(15)$ & $15(27)$ & $18(12)$ & $35(14)$ \\
\hline$\geqslant 50$ & $387(85)$ & $40(73)$ & $130(88)$ & $217(86)$ \\
\hline \multicolumn{5}{|l|}{ Grade } \\
\hline 1 & 77 (17) & & $22(15)$ & $55(22)$ \\
\hline 2 & $209(46)$ & $5(9)$ & 66 (45) & $138(55)$ \\
\hline 3 & $168(37)$ & $50(91)$ & $60(40)$ & $58(23)$ \\
\hline Unknown & $1(<1)$ & & & $1(<1)$ \\
\hline \multicolumn{5}{|l|}{ Lymph node } \\
\hline 0 & $311(68)$ & $36(66)$ & $94(64)$ & $181(72)$ \\
\hline $1-3$ & 97 (21) & $11(20)$ & 31 (21) & $55(22)$ \\
\hline$>3$ & $46(10)$ & $8(14)$ & $23(15)$ & $15(6)$ \\
\hline Unknown & $1(<1)$ & & & $1(<1)$ \\
\hline \multicolumn{5}{|l|}{ Size $(\mathrm{mm})$} \\
\hline$<20$ & $254(56)$ & $18(33)$ & $74(51)$ & $162(64)$ \\
\hline $20-50$ & 176 (39) & $35(64)$ & $61(41)$ & $80(32)$ \\
\hline$>5$ & $13(3)$ & $2(3)$ & $8(5)$ & $3(1)$ \\
\hline Unknown & $12(3)$ & & $5(3)$ & $7(3)$ \\
\hline \multicolumn{5}{|c|}{ ER Allred score } \\
\hline$<3$ & $57(12)$ & $55(100)$ & $2(1)$ & \\
\hline $3-5$ & $21(5)$ & & $21(14)$ & \\
\hline $6-8$ & $377(83)$ & & $125(85)$ & $252(100)$ \\
\hline \multicolumn{5}{|c|}{ PR Allred score } \\
\hline$<3$ & $111(24)$ & $55(100)$ & $56(38)$ & \\
\hline $3-5$ & $90(20)$ & & $90(61)$ & \\
\hline $6-8$ & $254(56)$ & & $2(1)$ & $252(100)$ \\
\hline \multicolumn{5}{|l|}{ HER2 } \\
\hline Positive & $70(15)$ & $18(33)$ & $35(24)$ & $17(7)$ \\
\hline Negative & $382(84)$ & $37(67)$ & $111(75)$ & 234 (93) \\
\hline Unknown & $3(<1)$ & & $2(1)$ & $1(<1)$ \\
\hline \multicolumn{5}{|c|}{ Surgical operation } \\
\hline Mastectomy & $131(29)$ & $24(44)$ & $44(30)$ & $63(25)$ \\
\hline Conservation & $324(72)$ & $31(56)$ & $104(70)$ & $189(75)$ \\
\hline \multicolumn{5}{|c|}{ Endocrine therapy } \\
\hline Yes & $392(86)$ & $2(4)$ & $140(95)$ & 250 (99) \\
\hline Tamoxifen & $184(40)$ & & 57 (39) & $127(50)$ \\
\hline $\mathrm{Al}$ & 138 (30) & $2(4)$ & 57 (39) & $79(31)$ \\
\hline Early switch & $46(10)$ & & $14(9)$ & $32(12)$ \\
\hline Late switch & $24(5)$ & & $12(8)$ & $12(5)$ \\
\hline No & $63(14)$ & $53(96)$ & $8(5)$ & $2(<1)$ \\
\hline \multicolumn{5}{|c|}{ Chemotherapy } \\
\hline Yes & $166(37)$ & $40(73)$ & $59(40)$ & $67(27)$ \\
\hline No & $289(63)$ & $15(27)$ & $89(60)$ & $185(73)$ \\
\hline \multicolumn{5}{|c|}{ Biological therapy } \\
\hline Yes & $50(11)$ & $14(25)$ & $24(16)$ & $12(5)$ \\
\hline No & 405 (89) & 41 (75) & $124(84)$ & 240 (95) \\
\hline \multicolumn{5}{|c|}{$\begin{array}{l}\text { Abbreviations: } \mathrm{Al}=\text { aromatase inhibitor; } C E R=\text { combined endocrine receptor; } E R= \\
\text { oestrogen receptor; } \mathrm{HER} 2=\text { human epidermal growth factor receptor } 2 ; \text { hi }=\text { high; imp= } \\
\text { impaired; neg = negative; } P R=\text { progesterone receptor. For the validation population study, } \\
\text { patient and tumour characteristics in the column titled 'total' are recategorised according to } \\
\text { the } \mathrm{CER} \text { classification. Patients received endocrine therapy in the form of tamoxifen } \\
\text { monotherapy, } \mathrm{Al} \text { monotherapy, early switch within } 5 \text { years Al-tamoxifen or vice versa and } \\
\text { extended switch, } 5 \text { years on Al switched to tamoxifen or vice versa. }\end{array}$} \\
\hline
\end{tabular}


A

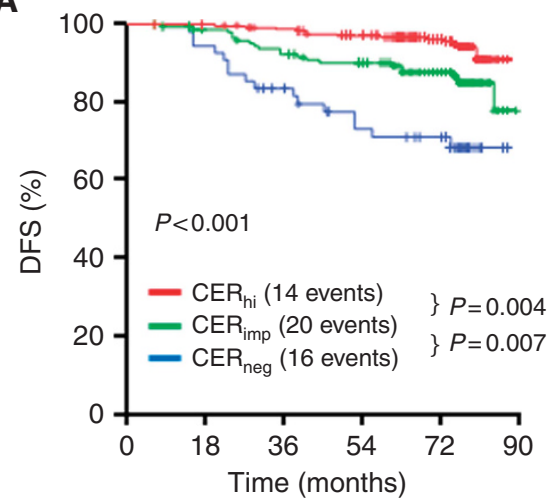

Number at risk

$\begin{array}{lllllll}\mathrm{CER}_{\mathrm{hi}} & 252 & 249 & 242 & 227 & 174 & 0\end{array}$

$\begin{array}{lllllll}\mathrm{CER}_{\text {imp }} & 148 & 140 & 129 & 120 & 94 & 0\end{array}$

$\begin{array}{lllllll}\text { CER }_{\text {neg }} & 55 & 51 & 42 & 33 & 29 & 0\end{array}$
B

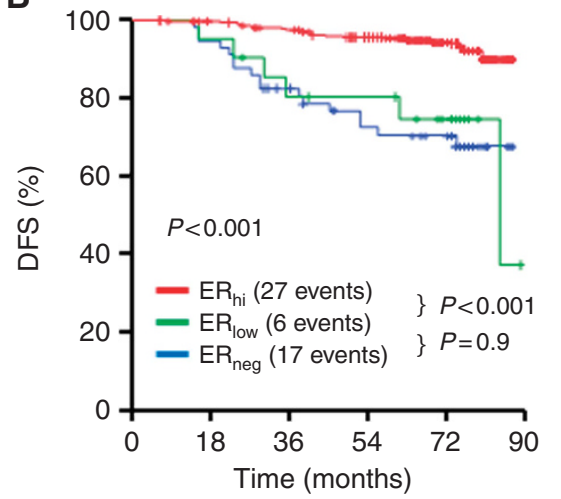

C

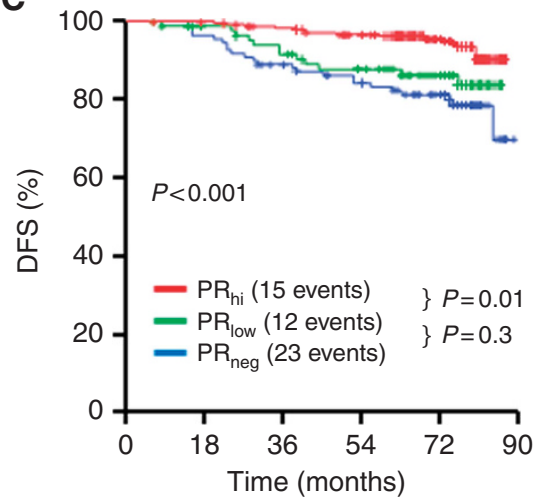

Number at risk

$\begin{array}{llllllllllllll}\mathrm{ER}_{\text {hi }} & 377 & 368 & 355 & 332 & 258 & 0 & \mathrm{PR}_{\text {hi }} & 254 & 252 & 243 & 228 & 175 & 0 \\ \mathrm{ER}_{\text {low }} & 21 & 20 & 16 & 14 & 10 & 0 & \mathrm{PR}_{\text {low }} & 90 & 83 & 76 & 67 & 50 & 0 \\ \mathrm{ER}_{\text {neg }} & 57 & 53 & 43 & 39 & 30 & 0 & \mathrm{PR}_{\text {neg }} & 111 & 106 & 95 & 86 & 72 & 0\end{array}$

Figure 3. Kaplan-Meier plots in the validation study. Five-year DFS was plotted according to the CER scores (A), ER scores (B) or PR scores (C). $\mathrm{Hi}=$ high; imp = impaired; neg $=$ negative .

intensity, both summated and as a product and concluded that the 'any-or-none' method was just as good at prediction and simpler. Certainly within our own study, the level of ER independently when analysed as negative, low and high did not have a linear relationship with outcome. However, when analysed as the combined endocrine receptor, a direct proportional benefit with outcome and level of receptors was identified. Higher amounts of hormone receptor levels as determined by IHC have been associated with improved patient outcomes (Cowen et al, 1990; Esteban et al, 1994; Barnes et al, 1996; Lockwood et al, 1999; Elledge et al, 2000; Stendahl et al, 2006; Yamashita et al, 2006; Dowsett et al, 2008). These studies suggest that patients with higher ER IHC levels will have a higher probability of good outcome, probably due to good response to endocrine therapy. Our study supports that the level of both hormone receptors is important for outcome.

While the predictive power of the ER is undisputed, the predictive power and clinical utility of $\mathrm{PR}$ is more controversial (Olivotto et al, 2004; Hefti et al, 2013). Since 2009 the UK National Institute of Clinical Excellence (NICE) no longer recommends PR measurement in routine pathological assessment of early breast cancer (National Institute for Health and, and Excellence, 2009). A number of studies have, however, reported the prognostic power of PR (Viale et al, 2007; Blows et al, 2010; Purdie et al, 2014; Mohammed et al, 2015). Our results are in keeping these studies demonstrating improved outcome in $\mathrm{ER}+/ \mathrm{PR}+$ breast cancer and support the value of PR measurement in breast cancer patients.

The aim of this study was simple, and combining the ER and PR will be more informative in terms of outcome than either independently. Our working hypothesis is that ER and PR should not be considered alone, both are required and semiquantitative IHC ER and PR scores together may represent a surrogate 'snap shot' of functional hormone receptor crosstalk. The importance of ER and PR being functionally linked through complex crosstalk has recently been defined (Mohammed et al, 2015). To our knowledge, we are the first study to report a combined ER and PR IHC. This was a retrospective study and relatively small in terms of patient numbers. We would urge for further testing and application in larger cohorts from different centres to validate this score. The cutoffs applied were based on consensus opinion of what is considered high and low receptor expression of ER and PR (Goldhirsch et al, 2009), and supported statistically to define the CER categories. Importantly, the cutoffs were robust in the validation cohort.
In conclusion, the CER is a more powerful predictor of patient outcome than either the ER or PR alone and is a simple and economical method to identify risk in ER + early breast cancer.

\section{ACKNOWLEDGEMENTS}

We are grateful to Prof Donald McMillan, University of Glasgow, Glasgow, United Kingdom and James Mansell for their contribution and support.

\section{CONFLICT OF INTEREST}

The authors declare no conflict of interest.

\section{REFERENCES}

Allred DC, Carlson RW, Berry DA, Burstein HJ, Edge SB, Goldstein LJ, Gown A, Hammond ME, Iglehart JD, Moench S, Pierce LJ, Ravdin P, Schnitt SJ, Wolff AC (2009) NCCN Task Force Report: estrogen receptor and progesterone receptor testing in breast cancer by immunohistochemistry. J Natl Compr Canc Netw 7(Suppl 6): S1-S21; quiz S2-S3.

Barnes DM, Harris WH, Smith P, Millis RR, Rubens RD (1996) Immunohistochemical determination of oestrogen receptor: comparison of different methods of assessment of staining and correlation with clinical outcome of breast cancer patients. Br J Cancer 74(9): 1445-1451.

Blows FM, Driver KE, Schmidt MK, Broeks A, van Leeuwen FE, Wesseling J, Cheang MC, Gelmon K, Nielsen TO, Blomqvist C, Heikkila P, Heikkinen T, Nevanlinna H, Akslen LA, Begin LR, Foulkes WD, Couch FJ, Wang X, Cafourek V, Olson JE, Baglietto L, Giles GG, Severi G, McLean CA, Southey MC, Rakha E, Green AR, Ellis IO, Sherman ME, Lissowska J, Anderson WF, Cox A, Cross SS, Reed MW, Provenzano E, Dawson SJ, Dunning AM, Humphreys M, Easton DF, Garcia-Closas M, Caldas C, Pharoah PD, Huntsman D (2010) Subtyping of breast cancer by immunohistochemistry to investigate a relationship between subtype and short and long term survival: a collaborative analysis of data for 10,159 cases from 12 studies. PLoS Med 7(5): e1000279.

Coates AS, Winer EP, Goldhirsch A, Gelber RD, Gnant M, Piccart-Gebhart M, Thurlimann B, Senn HJ (2015) -Tailoring therapies-improving the management of early breast cancer: St Gallen International Expert Consensus on the Primary Therapy of Early Breast Cancer 2015. Ann Oncol 26(8): 1533-1546. 
Cowen PN, Teasdale J, Jackson P, Reid BJ (1990) Oestrogen receptor in breast cancer: prognostic studies using a new immunohistochemical assay. Histopathology 17(4): 319-325.

Dowsett M, Allred C, Knox J, Quinn E, Salter J, Wale C, Cuzick J, Houghton J, Williams N, Mallon E, Bishop H, Ellis I, Larsimont D, Sasano H, Carder P, Cussac AL, Knox F, Speirs V, Forbes J, Buzdar A (2008) Relationship between quantitative estrogen and progesterone receptor expression and human epidermal growth factor receptor 2 (HER-2) status with recurrence in the Arimidex, Tamoxifen, Alone or in Combination trial. J Clin Oncol 26(7): 1059-1065.

Dowsett M, Cuzick J, Wale C, Forbes J, Mallon EA, Salter J, Quinn E, Dunbier A, Baum M, Buzdar A, Howell A, Bugarini R, Baehner FL, Shak S (2010) Prediction of risk of distant recurrence using the 21-gene recurrence score in node-negative and node-positive postmenopausal patients with breast cancer treated with anastrozole or tamoxifen: a TransATAC study. J Clin Oncol 28(11): 1829-1834.

Elledge RM, Green S, Pugh R, Allred DC, Clark GM, Hill J, Ravdin P, Martino S, Osborne CK (2000) Estrogen receptor (ER) and progesterone receptor (PgR), by ligand-binding assay compared with ER, PgR and pS2, by immunohistochemistry in predicting response to tamoxifen in metastatic breast cancer: a Southwest Oncology Group Study. Int J Cancer 89(2): 111-117.

Esteban JM, Ahn C, Mehta P, Battifora H (1994) Biologic significance of quantitative estrogen receptor immunohistochemical assay by image analysis in breast cancer. Am J Clin Pathol 102(2): 158-162.

Fisher ER, Anderson S, Dean S, Dabbs D, Fisher B, Siderits R, Pritchard J, Pereira T, Geyer C, Wolmark N (2005) Solving the dilemma of the immunohistochemical and other methods used for scoring estrogen receptor and progesterone receptor in patients with invasive breast carcinoma. Cancer 103(1): 164-173.

Goldhirsch A, Ingle JN, Gelber RD, Coates AS, Thurlimann B, Senn HJ (2009) Thresholds for therapies: highlights of the St Gallen International Expert Consensus on the primary therapy of early breast cancer 2009. Ann Oncol 20(8): 1319-1329.

Hefti MM, Hu R, Knoblauch NW, Collins LC, Haibe-Kains B, Tamimi RM, Beck AH (2013) Estrogen receptor negative/progesterone receptor positive breast cancer is not a reproducible subtype. Breast Cancer Res 15(4): R68.

Horwitz KB, McGuire WL (1975) Predicting response to endocrine therapy in human breast cancer: a hypothesis. Science 189(4204): 726-727.

Lockwood CA, Ricciardelli C, Raymond WA, Seshadri R, McCaul K, Horsfall DJ (1999) A simple index using video image analysis to predict disease outcome in primary breast cancer. Int J Cancer 84(3): 203-208.

Mohammed H, Russell IA, Stark R, Rueda OM, Hickey TE, Tarulli GA, Serandour AA, Birrell SN, Bruna A, Saadi A, Menon S, Hadfield J, Pugh M, Raj GV, Brown GD, D'Santos C, Robinson JL, Silva G, Launchbury R, Perou CM, Stingl J, Caldas C, Tilley WD, Carroll JS (2015) Progesterone receptor modulates ERalpha action in breast cancer. Nature 523(7560): 313-317.
Mohammed ZM, Edwards J, Orange C, Mallon E, Doughty JC, McMillan DC, Going JJ (2012a) Breast cancer outcomes by steroid hormone receptor status assessed visually and by computer image analysis. Histopathology 61(2): 283-292.

Mohammed ZM, Going JJ, McMillan DC, Orange C, Mallon E, Doughty JC, Edwards J (2012b) Comparison of visual and automated assessment of HER2 status and their impact on outcome in primary operable invasive ductal breast cancer. Histopathology 61(4): 675-684.

National Institute for Health and Care Excellence (2009) CG80 Early and Locally Advanced Breast Cancer: Full Guideline (NICE). Published online.

Olivotto IA, Truong PT, Speers CH, Bernstein V, Allan SJ, Kelly SJ, Lesperance ML (2004) Time to stop progesterone receptor testing in breast cancer management. J Clin Oncol 22(9): 1769-1770.

Paik S, Tang G, Shak S, Kim C, Baker J, Kim W, Cronin M, Baehner FL, Watson D, Bryant J, Costantino JP, Geyer Jr CE, Wickerham DL, Wolmark N (2006) Gene expression and benefit of chemotherapy in women with node-negative, estrogen receptor-positive breast cancer J Clin Oncol 24(23): 3726-3734.

Purdie CA, Quinlan P, Jordan LB, Ashfield A, Ogston S, Dewar JA, Thompson AM (2014) Progesterone receptor expression is an independent prognostic variable in early breast cancer: a population-based study. Br J Cancer 110(3): 565-572. SIGN (2007) S.I.G.N. Management of breast cancer in women (SIGN Guideline No 84). pp 1-52.

Stendahl M, Ryden L, Nordenskjold B, Jonsson PE, Landberg G, Jirstrom K (2006) High progesterone receptor expression correlates to the effect of adjuvant tamoxifen in premenopausal breast cancer patients. Clin Cancer Res 12(15): 4614-4618.

Torre LA, Bray F, Siegel RL, Ferlay J, Lortet-Tieulent J, Jemal A (2015) Global cancer statistics, 2012. CA Cancer J Clin 65(2): 87-108.

Viale G, Regan MM, Maiorano E, Mastropasqua MG, Dell'Orto P, Rasmussen BB, Raffoul J, Neven P, Orosz Z, Braye S, Ohlschlegel C, Thurlimann B, Gelber RD, Castiglione-Gertsch M, Price KN, Goldhirsch A, Gusterson BA, Coates AS (2007) Prognostic and predictive value of centrally reviewed expression of estrogen and progesterone receptors in a randomized trial comparing letrozole and tamoxifen adjuvant therapy for postmenopausal early breast cancer: BIG 1-98. J Clin Oncol 25(25): 3846-3852.

Yamashita H, Yando Y, Nishio M, Zhang Z, Hamaguchi M, Mita K, Kobayashi S, Fujii Y, Iwase H (2006) Immunohistochemical evaluation of hormone receptor status for predicting response to endocrine therapy in metastatic breast cancer. Breast Cancer 13(1): 74-83.

This work is published under the standard license to publish agreement. After 12 months the work will become freely available and the license terms will switch to a Creative Commons AttributionNonCommercial-Share Alike 4.0 Unported License.

Supplementary Information accompanies this paper on British Journal of Cancer website (http://www.nature.com/bjc) 